\title{
Study on the Influence of Micro - car on Compressive Strength of Roof
}

\author{
Changye Liu ${ }^{1,2, a}$, Yimin Mo ${ }^{2, b}$, Yong Wei ${ }^{1, c}$, Juncheng Lv ${ }^{1, d}$, \\ Yongbin Liang 2, e, Feng Wang ${ }^{2, f}$ \\ 1. AIC-GM-Wuling Automobile Co., Ltd., Liuzhou 545007, China; \\ 2.Wuhan University of Technology, Wuhan 430070, China. \\ aCChangye.Liu@sgmw.com.cn, ${ }^{\text {bmmoyimin@@whut.edu.cn, }{ }^{c} Y o n g . W e i @ s g m w . c o m . c n, ~}$ \\ dJuncheng.Lv@sgmw.com.cn, e502637785@qq.com , fFeng.wang@sgmw.com.cn
}

\begin{abstract}
Key words: Roof Strength; Rigid Wall; Thickness Optimization; Orthogonal Test; FMVSS 216a
Abstract. Firstly, the finite element model of a certain car is established, and then according to the regulations and standards of FMVSS 216a's "top compressive strength of passenger car", the test simulation analysis for ceiling compressive strength is presented. By comparing the energy curve, the accuracy of the simulation model is verified. A large number of simulation experiments on key parts of car body, such as, the upper and lower ends of the A-pillar, B- pillar and roof beam, are conducted in this paper. The goal is to do the research on the relationship between the thicknesses of these key parts and the compressive strength of the roof. According to the result of orthogonal experiment analysis, it is concluded that the influence of the key parts is Upper of B-pillar>Lower of A-pillar>Beam before the wind>Roof beam>Upper of A-pillar>Lower of B-pillar; Which play a major role in key parts is the B-pillar side. The optimization for key parts of car body is achieved, obtaining the best optimization program, so that compressive strength and safety margin of the roof are improved.
\end{abstract}

\section{Introduction}

In recent years, based on the road traffic safety bureau statistical analysis, automobile rollover accident has become the second largest traffic accident besides the car frontal crash accident. The rolling accident can cause a group of dead and wounded in the accident, and a serious impact on social and economic benefits [1-3].

Automotive roof compressive strength analysis experiment through the finite element analysis of the car roof strength assessment, testing the car whether has enough strength to resist the occurrence of large deformation to ensure the safety of passengers[4-5]. Based on the FMVSS 216a "Car roof compressive strength" regulatory standard, this paper uses the finite element simulation to analyze the deformation of the automobile body in the test, and uses the orthogonal experiment method to study the compressive strength of the critical part thickness and the optimal design of the key components is provided, which can provide the reference for the design of the compressive strength of the top of the miniature car.

\section{Establishment of Finite Element Model}

\section{Finite Element Model}

First of all, the vehicle finite element model is established, and then based on the latest FMVSS 216a "car roof compressive strength" regulatory standards, the test load device modeling and related 
settings, including the establishment of rigid walls and relative position adjustment, vehicle bottom Of rigid constraints and so on.

\section{Vehicle modeling}

When the meshing is carried out, the geometric model is simplified and the topology structure is refined to improve the quality of the meshing. Mesh size is one of the factors which affect the calculation accuracy and speed of LS-DYNA. In the main force parts, such as roof, A-pillar, B-pillar, front door and so on, the grid size is set to $8 \mathrm{~mm}$, the other parts set to $10 \mathrm{~mm}$., which can improve the calculation accuracy and efficiency[6-7].

\section{Loading Device Modeling}

The experimental device is shown in Figure 1. From the side to see the vertical axis and horizontal angle of $5^{\circ}$ down;horizontal abscissa for the horizontal down $25^{\circ}$ (face up). The vertical center line corresponds to the center of the contact area of the roof, and the distance between the leading edge and the roof is at $254 \pm 10 \mathrm{~mm}$ [8-9].

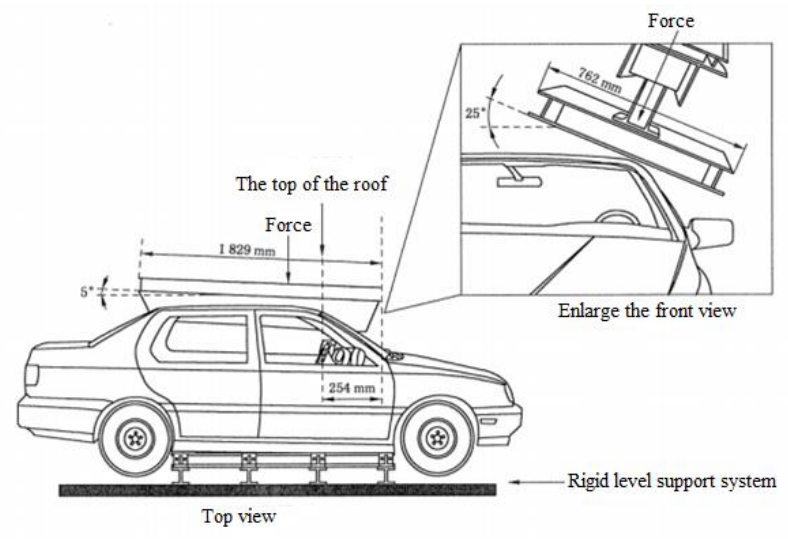

Fig.1 Experiment Device Schematic Diagram

\section{Constraint set}

According to Figure 1, the bottom of the vehicle will be rigid and rigid constraints. In the left and right sides of the body on both sides, the threshold and the lower beam to the vehicle $\mathrm{Z}$ to impose constraints on each side of 3 , total of 6 .

\section{The analysis of Simulation and Experiment}

Figure 2 shows the load-displacement curve of the rigid wall of simulation and experiment top pressure test. When the mass force is 3 times, the displacement of the simulated and experimental rigid wall is $67.2 \mathrm{~mm}$ and $74.0 \mathrm{~mm}$, both are in compliance with regulatory requirements.

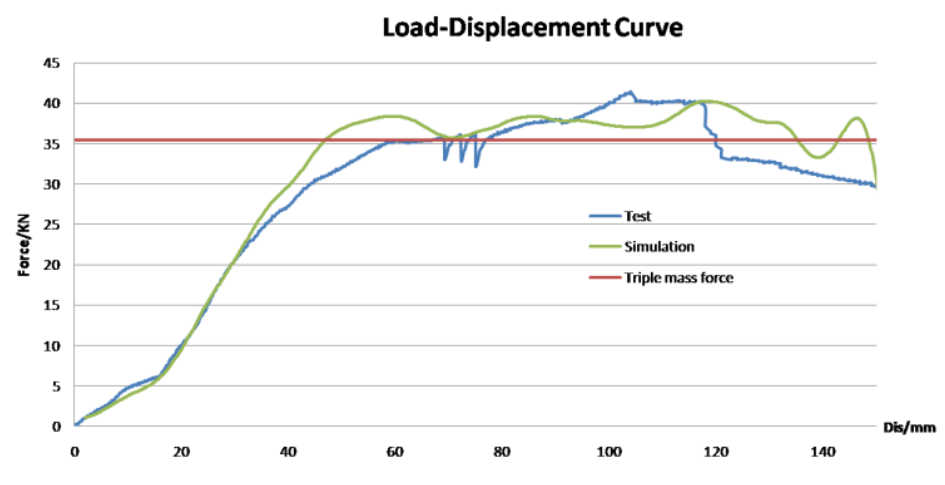

Fig.2 Real Vehicle and Simulation Load - Deformation Curve

From the deformation of the parts, the top cover, A column, B column, door frame deformation is large; the roof of a serious intrusion into the living space, B column has obvious bending 
deformation, front door lock to the door along the deformation is very large, front door and sliding door position obvious cracks. The main deformation of the comparison of simulation and experiment are shown in Figure 3.
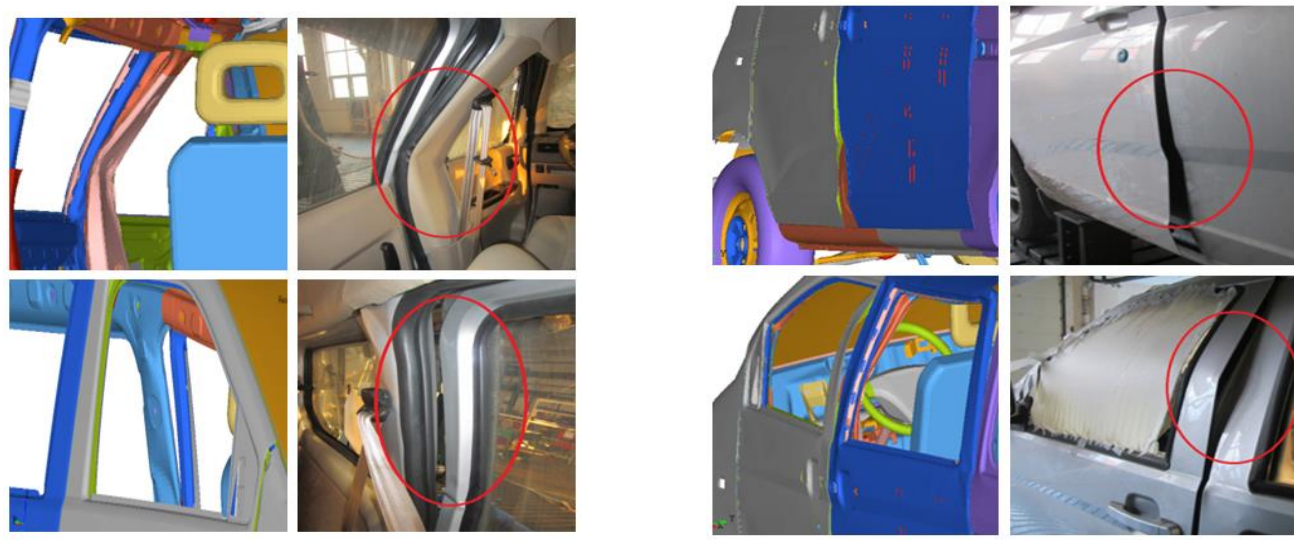

Fig.3 The Main Deformation Part

Through above analysis, the load-deformation curve and the deformation of key components meet the error requirement in the simulation, and the model has sufficient accuracy. Through the key parts of the vehicle model and the rigid wall contact, the transmission path of the force in the process of the rigid wall is obtained. At the same time, the key structure leading to the deformation of the vehicle body is A column, B column and roof beam.

\section{Researches on the Influence factors}

Through the analysis of the force transmission path of the top pressure model, in order to guide the deformation of the corresponding structural parts, it is necessary to design the key supporting structure of the automobile body reasonably [10-11]. The transmission path of the collision force is divided into X-direction, Y-direction, Z-direction, and 45-degree angle, in which the top beam, the A-pillar and the B-pillar are the main transmission path Optimized design. Therefore, the designs of the three parts need to be optimized. The optimizations plan are as follows: Option 1, thickening of the A pillar, (1) and (2) from the original 1.2,1.0 mm were increased to 1.4,1.2 $\mathrm{mm}$; Option 2, thickening of the B pillar, (3)and(4) from the original 1..0,1.2 mm were increased to 1.2,1.4 mm; Option 3, thickening of the roof beam(Including front cross beams), (5) and (6) from the original $1.0,0.8 \mathrm{~mm}$ were increased to $1.2,1.0 \mathrm{~mm}$.

Figure 4 shows the load-displacement curve of the rigid wall. The maximum displacement of the three times the quality of equipment is: $45.51 \mathrm{~mm}, 45.90 \mathrm{~mm}, 49.0 \mathrm{~mm}$; the maximum rigid wall load is: $41.11 \mathrm{KN}, 43.14 \mathrm{KN}, 42.08 \mathrm{KN}$.

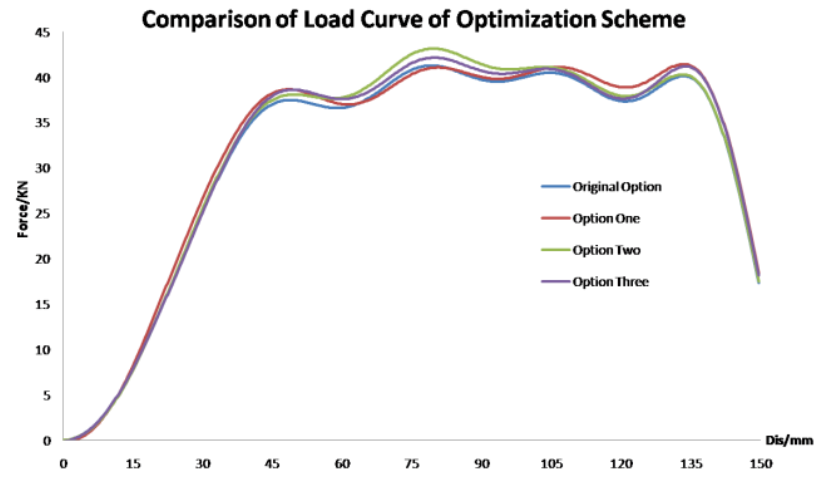

Fig.4 Optimization Scheme of Load Deformation Curve Contrast

The thickness optimization has a certain effect on the compressive strength of the roof, but the 
specific influence of the key parts is unknown. In the following, the different thickness values were set for the key structures in the three optimization schemes, and then carrying on orthogonal experimental design, study the influence of the thickness on the compressive strength.

\section{Orthogonal Experimental Designs}

\section{Ensuring Test Targets}

According to the analysis of the transmission path of the force and the design of the comprehensive factor test, through the optimization design of the A column, the B column and the roof beam, the ratio of the energy absorption of the body to the original model is taken as the test target when the rigid wall displacement is $127 \mathrm{~mm}$. The results are as follows: $\mathrm{Y}=(\mathrm{E} 2-\mathrm{E} 1)$ / E1,wherein: E1 is for representing the optimization of the former rigid wall displacement up to $127 \mathrm{~mm}$ vehicle energy absorption, E2 is for representing the optimization of the rear rigid wall displacement up to $127 \mathrm{~mm}$ vehicle energy absorption, The negative sign does not have the effect of optimization.

\section{Ensuring Test Factor and Level}

Through a large number of simulation experiments show that the car A pillar (upper and lower), B pillar (upper and lower), roof beams (front cross beam and roof beam) on the roof compressive strength have a greater impact. Therefore, the selection of these six key parts as the six factors of the test, each factor selected 7 levels of research, according to Table 1 select the horizontal parameters; that this experiment using 6 factors 7 level orthogonal test, using L49 (67) orthogonal Table [12].

Tab.1 The Orthogonal Experiment Design and Result

\begin{tabular}{llllllllll}
\hline Test & A1 & A2 & B3 & B4 & D5 & D6 & 7 & 8 & Y \\
\hline 1 & 1.0 & 0.8 & 0.8 & 1.0 & 0.6 & 0.8 & 1 & 1 & -8.11 \\
2 & 1.0 & 0.9 & 0.9 & 1.1 & 0.7 & 0.9 & 2 & 2 & -3.41 \\
3 & 1.0 & 1.0 & 1.0 & 1.2 & 0.8 & 1.0 & 3 & 3 & -0.78 \\
$\ldots$ & $\ldots$ & $\ldots$ & $\ldots$ & $\ldots$ & $\ldots$ & $\ldots$ & $\ldots$ & $\ldots$ & $\ldots$ \\
$\ldots$ &.. & $\ldots$ & $\ldots$ & $\ldots$ & $\ldots$ & $\ldots$ & $\ldots$ & $\ldots$ & $\ldots$ \\
$\ldots$ &.. & $\ldots$ & $\ldots$ & $\ldots$ & $\ldots$ & $\ldots$ & $\ldots$ & $\ldots$ & $\ldots$ \\
48 & 1.6 & 1.3 & 1.2 & 1.3 & 0.8 & 0.9 & 1 & 7 & 6.01 \\
49 & 1.6 & 1.4 & 1.3 & 1.4 & 0.9 & 1.0 & 2 & 1 & 8.96 \\
K1 & -0.0686 & 3.225 & -0.4 & 2.6529 & 0.7029 & 1.7943 & 3.385 & 3.085 & \\
K2 & 2.2971 & 3.28 & 1.3071 & 3.25 & 2.0571 & 2.6814 & 3.202 & 3.368 & \\
K3 & 2.1471 & 2.995 & 2.3029 & 2.8286 & 3.5714 & 2.7971 & 3.665 & 3.615 & \\
K4 & 3.1957 & 2.412 & 3.2929 & 3.1271 & 3.41 & 4.15 & 2.861 & 3.212 & \\
K5 & 4.2014 & 2.884 & 3.71 & 3.4171 & 3.7071 & 3.1471 & 3.395 & 3.055 & \\
K6 & 4.8986 & 3.49 & 5.5186 & 3.5471 & 4.3814 & 3.8086 & 2.907 & 3.434 & \\
K7 & 5.8171 & 4.2 & 6.7571 & 3.6657 & 4.6586 & 4.11 & 3.07 & 2.715 & \\
R value & 5.89 & 1.79 & 7.16 & 1.01 & 3.96 & 2.36 & 0.8 & 0.9 & \\
weight & 2 & 5 & 1 & 6 & 3 & 4 & 8 & 7 & \\
Better & $\mathrm{A} 17$ & $\mathrm{~A} 27$ & $\mathrm{~B} 37$ & $\mathrm{~B} 47$ & $\mathrm{D} 57$ & $\mathrm{D} 64$ & Error column & \\
\hline
\end{tabular}

From the table it can be seen the car A pillar (upper and lower), B pillar (upper and lower),the greater the thickness, the better the optimization effect. The main factors are B3> A1> D5> D6> A2 $>$ B4, that's the upper of B-pillar> the lower of A-pillar > the front cross beam $>$ the roof beam > the upper of A-pillar> the lower of B-pillar; The optimal level of each factor is: A17A27B37B47D57D64 (subscript is the level), that is the upper and lower ends of the A column, the upper and lower ends of the column, the front cross beam, the roof beam are $1.6 \mathrm{~mm}, 1.4 \mathrm{~mm}$, $1.4 \mathrm{~mm}, 1.6 \mathrm{~mm}, 1.2 \mathrm{Mm}, 1.1 \mathrm{~mm}$, Optimization of the best. 


\section{Variance Analysis}

Tab.2 Analysis of Variance Table

\begin{tabular}{cccccc}
\hline $\begin{array}{c}\text { Source of } \\
\text { variance }\end{array}$ & Square sum of variance & $\begin{array}{c}\text { Degrees of } \\
\text { freedom }\end{array}$ & Mean square error & $\begin{array}{c}\text { F } \\
\text { value }\end{array}$ & $\begin{array}{c}\text { Significant } \\
\text { level }\end{array}$ \\
\hline A1 & 163.405 & 6 & 27.234 & 45.35 & $1.4768 \mathrm{E}-7$ \\
A2 & 12.957 & 6 & 2.160 & 3.596 & 0.0282 \\
B3 & 249.511 & 6 & 41.585 & 69.25 & $1.3047 \mathrm{E}-8$ \\
B4 & 5.800 & 6 & .967 & 1.610 & 0.2271 \\
D5 & 80.522 & 6 & 13.420 & 22.34 & $7.4331 \mathrm{E}-6$ \\
D6 & 31.569 & 6 & 5.262 & 8.762 & $8.1594 \mathrm{E}-4$ \\
Error & 7.206 & 12 & .601 & & \\
Sum & 550.971 & 48 & & & \\
\hline
\end{tabular}

From Table 2, the significant levels of factors B3, A1, D5, D6 are less than 0.01, that is B3, A1, D5, D6 have a significant effect on the experimental optimization result; the significant level of factor A2 is less than 0.05, The effect is significant; the significant level of B4 is less than 0.1, B4 has no significant effect on the experimental optimization result (can be regarded as error or negligence). The main factors of influence are: B3> A1> D5> D6> A2> B4, and the variance is consistent with the result of the difference analysis.

\section{Verification of Results}

Modifying the model, the micro-car upper and lower of A and B pillar, the front cross beam and the roof beam thickness were set to $1.6 \mathrm{~mm}, 1.4 \mathrm{~mm}, 1.4 \mathrm{~mm}, 1.6 \mathrm{~mm}, 1.2 \mathrm{~mm}, 1.1 \mathrm{~mm}$, The results show that rigid wall at three times the mass force displacement is $37.20 \mathrm{~mm}(67.20 \mathrm{~mm}$ before optimization), the maximum load is $49.0 \mathrm{KN}$ (40.12 before the optimization), the energy absorption is $4554.17 \mathrm{KN} . \mathrm{mm}$ (before optimization is $4072.61 \mathrm{KN} . \mathrm{mm}$ ), the optimization effect is $11.82 \%$. The optimization of the front and rear rigid wall displacement and body energy curve comparison is shown in Fig.6 and Fig.7.

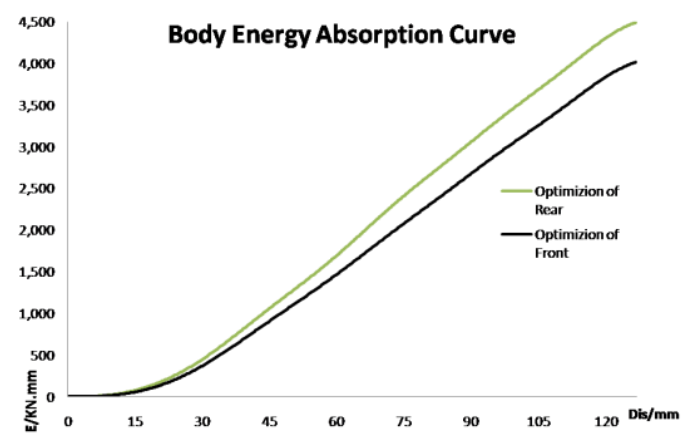

Fig.6 Rigid Wall Displacement Contrast Before and After Optimization

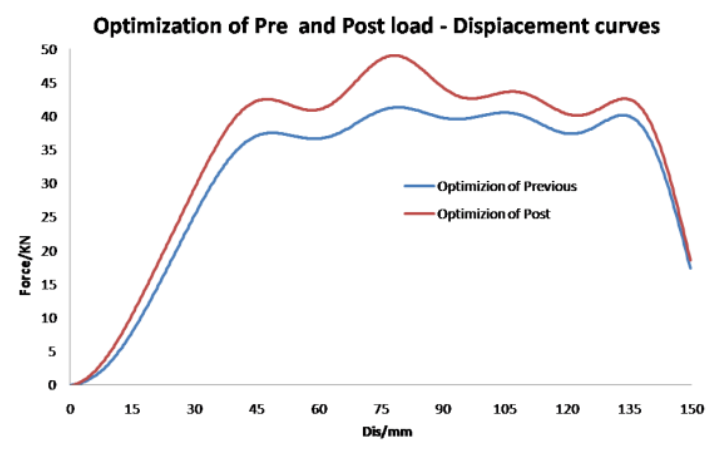

Fig.7 Body Energy Absorption Curve Comparison Before and After optimization

\section{Conclusion}

According to the latest FMVSS 216a regulations in the United States, this paper establishes a finite element model of a miniature vehicle and simulates the corresponding simulation. Through the optimization scheme design and the orthogonal test results shows:

(1) The key parts of the deformation of the roof are the A-pillar, the B-pillar, the roof beam, etc. The miniature car in the design and manufacture should focus on the key parts of the strength of the design.

(2) In the optimization of the thickness of the A-pillar, the B-pillar and the top beam, the influence of the key parts is the upper of B-pillar> the lower of A pillar> the front cross beam>the 
roof beam > the upper of A-pillar> the lower of B-pillar; The role of the upper part of the B-pillar, so the B column optimization effect is more prominent, more conducive to enhance the roof compression performance. the upper of B-pillar plays a major role, so the B column optimization effect is more prominent, more conducive to enhance the roof compression performance.

(3) According to a large number of simulation data, the intrusion does not decrease with the increase of the thickness of the key parts, and the maximum load of the rigid wall increases with the increase of the thickness. In view of the above, the upper and lower of A and B pillar, the front cross beam and the roof beam thickness were set to $1.6 \mathrm{~mm}, 1.4 \mathrm{~mm}, 1.4 \mathrm{~mm}, 1.6 \mathrm{~mm}, 1.2 \mathrm{~mm}, 1.1 \mathrm{~mm}$ were the best optimization results, Optimization effect $\mathrm{Y}$ is $11.82 \%$, rigid wall displacement $37.20 \mathrm{~mm}$, maximum load 49.0KN.

\section{References}

[1] Bo-yuan Xie.Auto rolling accident reappearance and test method. School of Automotive Studies.( In Chinses)

[2] STRASHNYA.An Analysis of Motor Vehicle Rollover Crashes and Injury Outcomes[R].National Highway Traffic SafetyAdminist, 2007.

[3] PG Bedewi,DA Godrick,KH Digges,GT Bahouth.AN INVESTIGATION OF OCCUPANTINJURY IN ROLLOVER:NASS-CDS ANALYSIS OF INJURY SEVERITY AND SOURCEBY ROLLOVER ATTIBUTES[C].18th International Technical Conference on the Enhanced on the Enhanced Safety of Vehicle ,Paper No.03-0419:National Highway Traffic Safety Administration,2003.

[4] Feng PAN, Ping Zhu, Si-liang Zhang. Research on Roof Crush Simulation and Structural Crashworthiness of Passenger Car .China Journal of Highway and Transport, 2010,03:108-114. ( In Chinses)

[5] Yang Wang, Teng-fei Bi Kun Wang, Pe-izhong Wang.The Standards Interpretation of Roof Crush Resistance. China Automotive Engineering Society.2013 China Automotive Engineering Society Proceedings of Conference [C],2013:4.( In Chinses)

[6] Huan He.Vehicle rolling simulation technology and application [D]. Chongqing University, 2007. ( In Chinses)

[7] Zhi-yuan Hu, Bi-qiang Zeng, Shu-gang Xie.Based on 1s-dyna and HyperWorks safety simulation and analysis [M]. Tsinghua University Press. (In Chinses)

[8] Wei Wang, Yong Xin. Frame Finite Element Modeling and Modal Analysis [J].Machinery Design \& Manufacture,2009,11:53-54( In Chinses)

[9] China automotive technology research center. GB 26134 a 2010 passenger cars at the top of the compressive strength [S]. Beijing: China standard Press, 2011

[10]Dong-sheng LV, Dong-fang Wang, Xiao-ping Su.Based HYPERWORKS of a bus frame finite element[J].Machinery Design \& Manufacture,2011,03:11-12. ( In Chinses)

[11]Guang Wu, Guang-yao Li, Tao Chen.Simplified FEM Modeling Method for Simulating Side Impact Based on Vehicle Side Structure. China Mechanical Engineering, 2009,20 (16) :1996-2001.) (In Chinses)

[12]Xi-wen Ma.The mathematical theory of orthogonal design. Beijing: People's Education Press. 1981:1-18. ( In Chinses) 